\title{
Green Economy and Indicators of Sustainable and Ecological Development
}

\section{Zoran Todorović ${ }^{1^{*}}$}

${ }^{1}$ D.o.o. Društvo za reviziju, procjenjivanje, vještačenje i usluge konsaltinga „Auditing-Mont“, Podgorica

\begin{abstract}
The need for global economic growth has raised the level of living standards around the world, and following this aspiration, all countries, both developed and developing countries, look at the growth rate of gross domestic product as a critical indicator of success and prosperity. The actions aimed at continuously increasing consumption have had a devastating impact on the global environment, exploiting natural resources without sufficiently considering the consequences that this exploitation leaves in the environment.

The national level, as far as the most responsible for the implementation of the Green Agenda, will have to make appropriate changes in fiscal policy, through the reform and elimination of subsidies that can be considered less favorable from the environmental aspects. A major step in this direction may be the adoption of policies and procedures for green public procurement and green accounts. At the supranational level, further efforts must be made to improve the situation on world markets, to promote the rules of free trade and the flows of international development assistance, and to further encourage international cooperation.
\end{abstract}

Key words: green economy, sustainable development, green economy policy, traditional economy, sustainable development indicators

JEL Classification: Q57

\section{INTRODUCTION}

The need for global economic growth has raised the level of living standards around the world, and following this aspiration, all developing countries, as well as developing countries, see the GDP growth rate as a critical indicator of success and prosperity. At the same time, the pursuit of economic growth and actions aimed at constant increase in consumption had a devastating impact on the global environment, the exploitation of natural resources without taking into account the consequences that this exploitation leaves in the environment, as well as the valuation of short-term financial gains in relation to the long-term the benefit of preserving some of the most prestigious and valuable ecosystems.

Climate change, the economic and energy crisis, and all the aforementioned problems imposes the need for radical socio-economic changes in the cities of the 21st century, in the direction of encouraging the so-called "green economy." The concept of green economy implies a widespread use of renewable energy sources, places and investments in the so-called green industries The Green Economy is defined as the one that emits little carbon, uses natural resources efficiently, and is socially inclusive Green economy creates great chances for sustainable development,

\footnotetext{
*E-mail: zoran.todorovic@auditing-mont.me
} 
which means increasing income, reducing poverty and improving the quality of life Green economy, especially renewable energy, is also crucial for reducing poverty, a particularly significant problem for developing countries.

The business community of each state must create preconditions for a green economy as an integral part of a broader concept of sustainable development to become one of the challenges to the challenges facing modern mankind.

\section{THE NOTION AND DEFINITION OF A GREEN ECONOMY}

The green economy has been promoted in recent decades as a very important change in thinking. As we look at the concept of a neoliberal economic paradigm, it is quite clear that something new is needed, but it is not always easy to translate it into practice. Neoliberal thinking has been transformed into the leading paradigm of development since the time of regulation and point of view through the reaffirmation of the Washington Consensus so that in one moment almost the power of a certain religion could be gained. This form of economic organization adopted, or even imposed on states around the world, was considered as one of the successful ways to achieve the human well-being within the framework of the concept of human rights and freedoms. The economic crisis, of which we are witnesses, has led to a deterioration in terms of economic development.

There are many ways to stop the process of destroying ecosystems and restoring it. What they have in common is the understanding that our global ecosystem must be evaluated in a different way and that it should be invested in the environment and services it provides and on which all human and economic activities depend. Finally, a "green economy" needs to be developed.

The concept of green economy is not new. It is only more and more mentioned in the last decade, bearing in mind that global interest in environmental issues is growing and that climate change is slowly taking over the primacy of the world's leading theme.

The UN Environment Program (UNEP) defines a green economy as an economy that has, as a result, enhanced human well-being and social equity, and significantly reduces environmental and ecological disadvantages. A simplified, green economy can be considered an economic activity that is carried out with low carbon emissions, through which resources are spent efficiently and socially inclusive. In the green economy, growth in earnings and employment is achieved through public or private investment that reduces carbon emissions and other pollution, achieves energy efficiency and efficiency in resource use, or prevents loss of biodiversity and ecosystem services. These investments should be directed and supported by targeted public expenditures, political reforms and legislative changes. The development framework should preserve, enlarge and, where necessary, rebuild natural capital reserves as a source of public benefit, especially for poor people whose living conditions and safety depend on nature.

\section{THEORETICAL FRAMEWORK}

Nevertheless, the most significant step in the development of economic theory was the appearance of the book "The Law of Entropy and the Economic Process" by Nicholas GeorgescuRoegen (1971). This study is based, a new look, based on thermodynamic concepts, is being further developed in the works of Mirowski (1989) and recently Beard and Lozada (1999). At the same time when Georgescu-Roegen's book appeared, the views of Meadows and associates (1972), devoted to the exhaustion of resources and the possible limits of growth, draw attention to the far wider circle of the world, scientific and political public. Thus, the concept of sustainable development is at the top of the priorities of international political action.

In Stockholm, in 1972, at the UN Environment Conference, the establishment of the United Nations Environment Program, UNEP, was initiated. This was followed by the establishment of 
national environmental agencies in a number of countries. With the coordinated action of national and international bodies, in 1980, a program of global action to promote sustainability was proclaimed. The World Conservation Strategy, by the International Union for the Conservation of Nature. Accordingly, in 1983, by the UN, the World Environment and Development Commission was established, later called the Brundtland Commission, by the name of the chairperson.

Seizing the danger of potential climate change, the World Meteorological Organization, the WMO and the UN Environment Program, UNEP, established the Interstate Panel on Climate Change in 1988, the IPCC, which, with its three working groups, aims to collect all relevant scientific, technical and socio-economic information related to anthropogenic climate change.

Numerous activities by state and non-governmental organizations around the world led in 1992 to the UN Conference on Environment and Development, UNCED in Rio de Janeiro. Important conference papers were adopted at this conference: UN Framework Convention on Climate Change and Convention on Biological Diversity. The following was established in 1993 by the UN Commission for Sustainable Development (CSD), with the primary objective of overseeing the implementation of the above mentioned documents and other acts. During the 1990s, the number of organizations aimed at fostering sustainable development was significantly expanded, among them the Committee of International Institutions for Development and Environment, CIDIE, and the World Resources Institute, WRI. Many of the existing international institutions, e.g. The Organization for Economic Cooperation and Development, the OECD and the World Bank, WB, are beginning to intensively encourage sustainable development.

\section{THE RELATIONSHIP OF GREEN ECONOMY AND SUSTAINABLE DEVELOPMENT}

The concept of green economy does not replace sustainable development, but today there is increasing evidence that the attainment of sustainable development goals depends to a large extent on developments in the economic sphere. Decades in which new values and well-being are real on principles and with the use of traditional economic models have not managed to tackle social marginalization and excessive resource consumption, and today we are still far from reaching the millennium development goals. Sustainability remains a first-class long-term goal, but additional efforts must be geared towards achieving the concept of a green economy if that goal is to be achieved.

Green economy in the context of sustainable development and environmental sustainability is a very important function in the development of society as well as the overall economic system of each state.

The basic ideas, which represent the term of sustainable development, are aggregated (World Bank, 2003; Coper \& Vargas, 200; Stead et al., 2004):

- Ecological and economic integration. Ensure that economic development and environmental protection are integrated at the same time in planning and implementation.

- Environmental Protection. Dedication reduces pollution and degradation of the environment and more efficient use of resources.

- Justice. Commitment meets at least the basic needs of the present poor generations (as well as equity between generations).

- Future events. Explicit concern about the impact of current activities on future generations.

- Quality of life. Realizing that human beings are concerned not only about income growth, but also about health and a sense of life satisfaction in their societies. 
- Participation. The realization that sustainable development requires the participation of all interest groups of society.

Sustainable development is an umbrella concept and a magnificent paradigm that connects economy, society and environmental protection, within which green growth strategies can be considered as an appropriate framework of practical policies. Bearing this in mind, it is clear that the green economy is something more concrete than sustainable development. The principles of sustainable development relate to long-term aspirations, while the green economy combines the aspirations for creating new opportunities that would lead to more robust economic recovery in the short run with the introduction of new, more environmentally efficient sources of economic growth in the long run.

What is most important: Green growth policies place emphasis on places where economic and environmental interests are touched or overlap and try to find the best development options in such a framework. Thus, the green economic growth strategies contribute to sustainable development by creating a better political framework, necessary for achieving the concept of sustainable development.

\section{ENVIRONMENTAL PERFORMANCE INDICATORS}

There is a growing demand for company reporting, which is clearly and focused on the key impacts of their business on the environment. This requires reporting on environmental performance, which will bring benefits in two ways:

- Provide information to management to utilize savings that a good environmental impact usually brings;

- It will provide the opportunity to discover important components in the company's environmental protection (Becker, 2008).

Environmental performance indicators are one of the tools for such measurements and information on how to understand and evaluate the environmental performance of companies. Enterprises will carry out significant environmental conservation activities if they can determine the appropriate performance indicators. Environmental indicators will facilitate communication with stakeholder ecological groups if they are involved in reporting. Through the application of environmental indicators, assessment and measurement of environmental conditions, a set of data is provided for information and assistance to governments, development coordinators, planners and decision makers in monitoring their impact on environmental sustainability (Bell \& Morse, 1999; Bel \& Morse, 2003). Environmental Performance Indicators (EPIs) have progressively developed over the past ten years and have been used by international organizations such as the United Nations, the World Bank, the World Business Council for Sustainable Development and the Global Reporting Initiative (OECD, 1993; Neimanis \& Kerr, 1996).

Environmental Performance Indicators stand out as an important tool for environmental protection and improvement of local life measurement and overall national development and sustainable development. Indicators cover a wide spectrum and are applied at the local, national and regional levels. Their users can easily access them, directly select them and immediately apply them to measure national ecological performance. In practice, indicators can help to make decisions on a global and national level.

The ecological series of ISO standards (International Organization for Standardization) is widely used in companies that implement environmental management, which outcomes have ecological performance reporting. This is especially true for the evaluation of environmental performance and the setting of a set of standards on a global level, which require constant commitment to improving environmental performance in order to meet environmental objectives and criteria. ISO 14031 and ISO 14032 are an extension of the ISO 14000 series. ISO 
14031 provides guidelines for the selection and realistic organizations to illustrate the use of the guidelines in ISO 14031 (Evaluation of Environmental Performance - Guidelines: Specification for the purpose of evaluating environmental performance, preparing the evaluation plan, collecting data, this is regulated as JIS Q 14031 on October 20, 2000). Although the Guideline defines the concept and procedure for selecting environmental performance indicators, it does not include the development of indicators themselves.

\section{IMPLEMENTATION OF INDIVIDUAL ESDP RECOMMENDATIONS}

The ESDP (European commision, 1999) is an "umbrella" document that regulates the spatial development of the territory of the European Union, through a number of different topics and through concrete advice and recommendations, which are the most useful at the level of programming tasks. As a country that is seeking to join the European Union, it is necessary for us to approach access to planning and spatial planning to better align with the principles that apply in the Union. In that sense, it is necessary to innovate the approach to creating program tasks in accordance with sustainable development and ESDP (European Spatial Development Perspective).

\section{Sustainable (green) economy}

According to the ESDP, a sustainable (green) economy contributes to:

- Strengthening co-operation on specific topics in the field of spatial development through cross-border and transnational networks;

- Improving the economic base, ecological and service infrastructure of cities, especially in underdeveloped regions, in order to increase their attractiveness for investments;

- Promoting the strategy of expanding the economy in cities that depend only on one branch of the economy and supporting the economic development of cities in underdeveloped regions;

- Strengthening of small and medium-sized cities in rural areas as centers for regional development and promotion of their networking;

- Strengthening networks between businesses and rapidly expanding innovation, especially with the help of regional institutions that can promote innovation;

- Promoting cooperation and information exchange between rural areas.

\section{Sustainable society}

According to the ESDP, a sustainable society means:

- Promotion of integrated urban development strategies that take into account social and functional diversity. Particular attention should be paid to combating social exclusion and recycling and / or restructuring of under-utilized or abandoned urban areas or areas;

- Assistance in finding effective methods for reducing uncontrolled urban expansion; reducing the excessive pressure of settlement, especially in coastal regions;

- Promotion of diverse development strategies, which take into account domestic potentials in rural areas and contribute to the achievement of domestic development (including promotion of multifunctionality of agriculture). Helping rural areas through education, training and job creation outside agriculture;

- Providing access at the European level to the knowledge infrastructure, taking into account the socio-economic potential of modern small and medium-sized enterprises as a driver of sustainable economic development; 
- A comprehensive public support as a necessary prerequisite for effective implementation

- access to spatial development policy;

Examples of principles and recommendations useful for creating program tasks 17 Extensive integration of knowledge-related policies, such as promotion innovation, education, vocational training and education, development research and technology, into spatial development policies, especially in remote areas or densely populated areas.

\section{Ecology}

According to the ESDP, the ecology includes:

- Promotion of rational management of urban ecosystems (Urban development leads to more productive agriculture, uncontrolled tourism - especially in coastal areas in the summer months, harmful infrastructure projects, which leads to loss of habitat, destruction, modification and fragmentation of ecosystems);

- Careful use of natural resources and implementation of protection measures;

- Cooperation at the national, regional and global levels;

- Providing sustainable agriculture, applying ecological measures and enriching the use of agricultural land;

- Exploiting the potential for renewable energy in urban and rural areas, taking into account local and regional conditions, especially cultural and natural heritage.

\section{RESEARCH FRAMEWORK}

The aim of this paper was to improve the preparation of program tasks for planning documents that are being made in Montenegro. The idea was that the principles of sustainable development and environmental protection integrate, as much as possible, into the content of the planning documents, one segment of which makes the development of program tasks. The main purpose is to improve the spatial planning system in Montenegro.

The new system should provide sustainable development through the rehabilitation of the consequences of space devastation, the rational use of resources and the preservation of the environment. In such a way, with sustainable spatial development, we will create a better place for living in Montenegro.

The most common reasons that lead to failure when creating program tasks:

- Insufficient knowledge and understanding of the sustainable concept spatial planning, which leads to a lack of harmonization of the guidelines in the framework the same dueling task;

- The lack of precisely defined measures of sustainable spatial planning as part of the program task, which leaves space for the future inadequate treatment, abuse and degradation of the space itself;

- Important absence of a reliable, thoughtful and generally accepted sequence guidelines and procedures that can provide quality planning;

- The lack of quality, applicable municipal development strategies that would based on the principles of sustainable development, and which would facilitate the creation software tasks.

\section{RESEARCH RESULTS}

Analysis of the survey for municipalities and state institutions 
The method of survey was used for the empirical part of the work, and data from municipalities and state authorities were collected through the questionnaire, which were analyzed further.

1.1. Objective of the research: To determine the level of understanding of the modern European approach to the preservation of the environment and sustainable development of the representatives of municipalities and state authorities through issues focused on knowledge of the term sustainable development, its principles, degree of application of existing legislation and emphasizing the most frequent problems in the field of environment 0 in Montenegro .

Period of realization; June-July 2011.

Number of respondents; 35 (municipalities - 21, state bodies - 14)

Report structure: The report is made up of two parts

PART I: Analysis of the survey intended for the municipalities in which 21 surveys from 21 municipalities were processed.

PART II: Analysis of the poll intended for state bodies dealing with environmental issues. 14 surveys were obtained from the competent state institutions: the Ministry of Sustainable Development and Tourism, the Environmental Protection Agency and the Office for Sustainable Development.

PART I Analysis of municipalities surveyed

1. The first question

1.1. The survey referred to the knowledge of the very term of sustainable development. Employees in municipalities were able to respond affirmatively, withholding or not being sure. In Chart 1, it can be seen that all surveyed / not familiar with the term sustainable development.

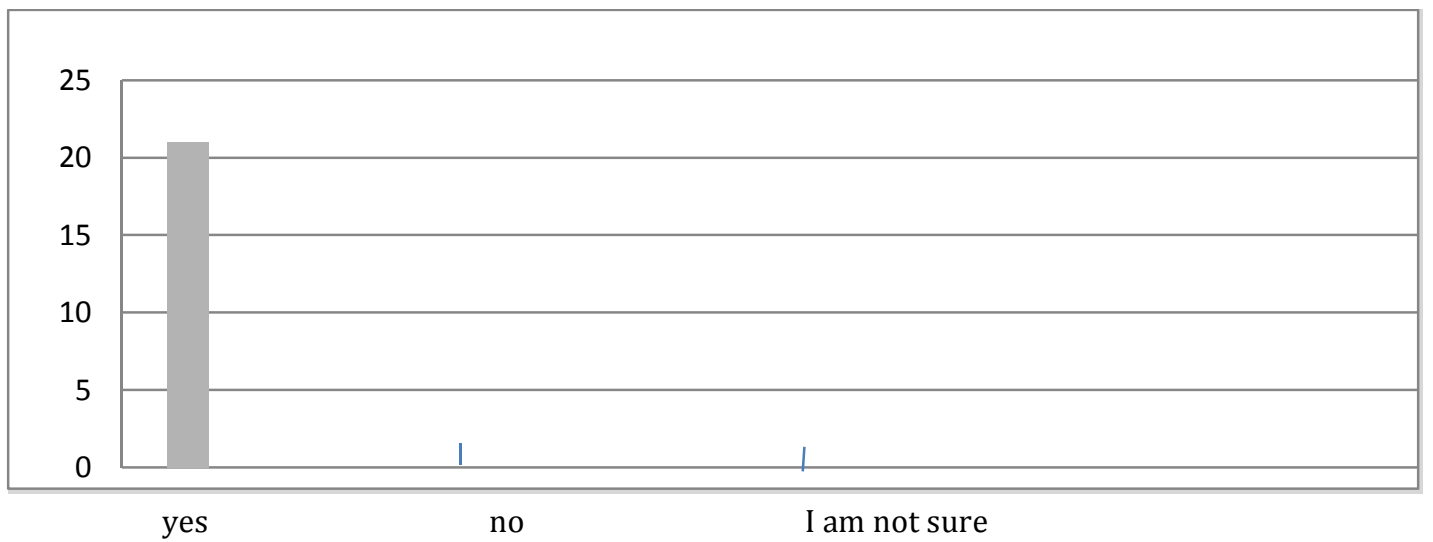

Chart 1: Do you know the term sustainable development?

1.1. In the second part of the first question, municipal employees were asked to indicate priority areas for sustainable development. Responses are offered: environmental protection, social development, economic development, all three areas. In addition, respondents / did not have the possibility to add other priority areas that are not mentioned in the issue itself. As can be seen in Chart 2 (on the next page), the vast majority emphasized that the priority areas of sustainable development are: environmental protection, social development and economic development.

2. The second question also consists of two parts. In the first part of the question, the respondents answered / did the question whether participants / participants in some trainings / seminars / conferences in the area of sustainable development. It was found out that 14 of the total of 21 respondents had a certain type of training, which can be clearly seen in Chart 3. 


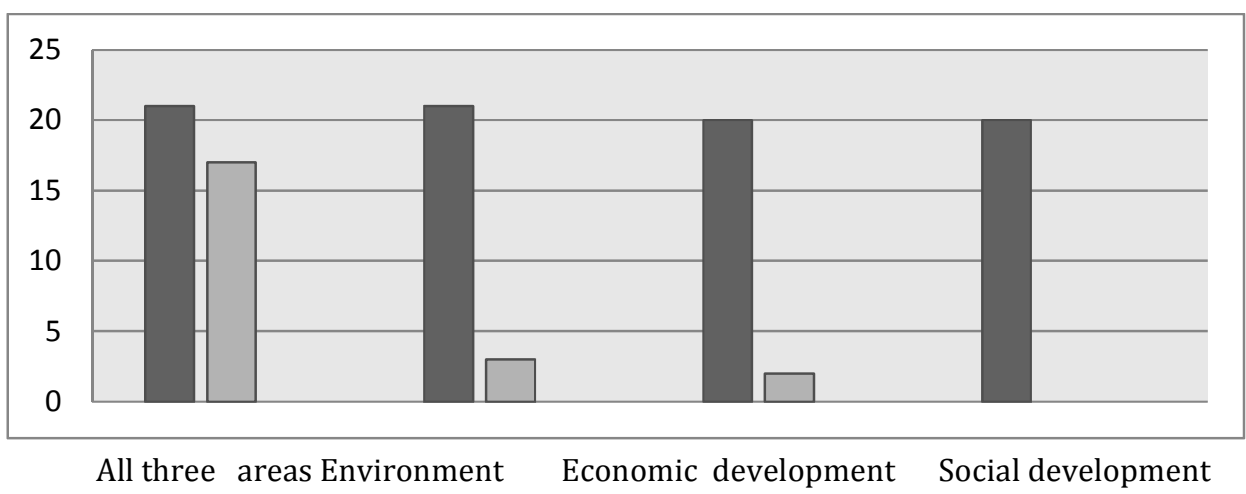

Chart 2: List the basic principles of sustainable development?

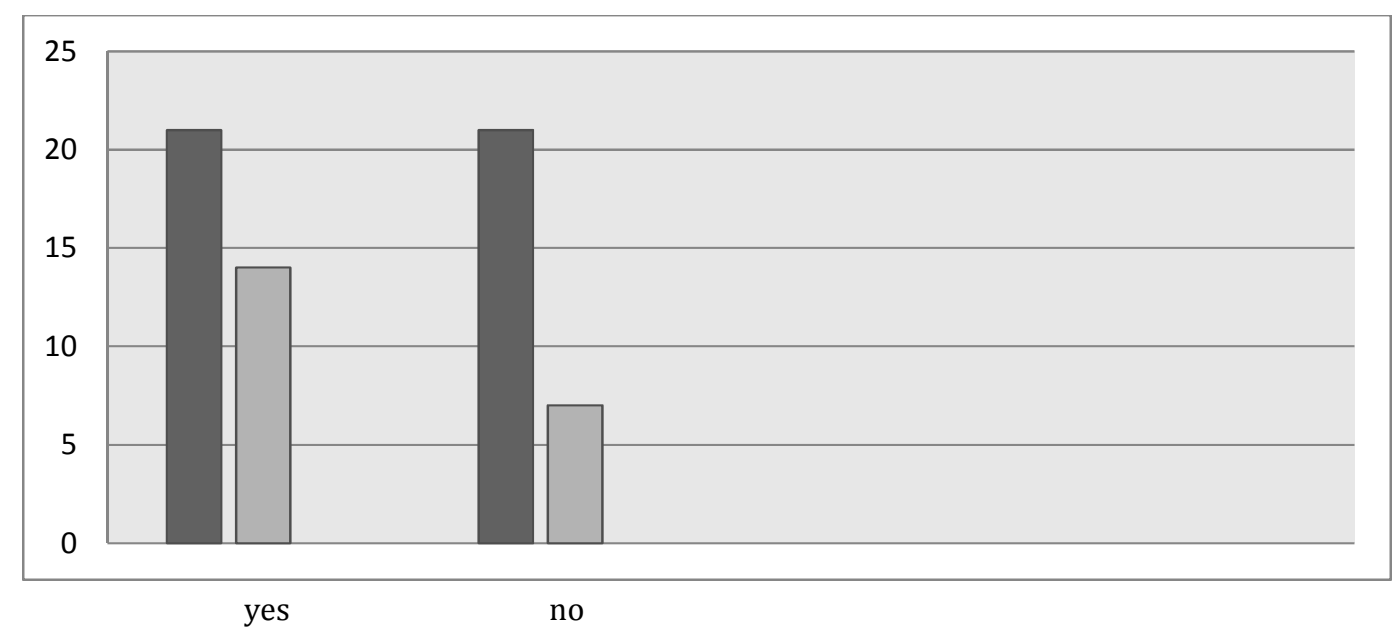

Chart 3: Have you been a participant in some trainings / seminars / conferences in the futility of sustainable development?

1. What was also interested in was how many employees in municipalities were familiar with the adoption of the Local Environmental Action Plans, the Local Agenda 21, the Local Sustainable Development Strategy or some other local strategic framework that regulates the issue of sustainable development, and in what percentage, according to In their opinion, the beneficiaries of this program have been applied. The collected data show that the above documents were presented in most municipalities (Chart 4), but also that in 8 municipalities they are applied in less than 50\%. Out of the total of 21 surveyed municipalities, 8 did not answer at all the part related to the implementation of local documents, which indicates that they either are not familiar with the situation in the municipality itself or are not interested in the application of the mentioned municipal documents. 


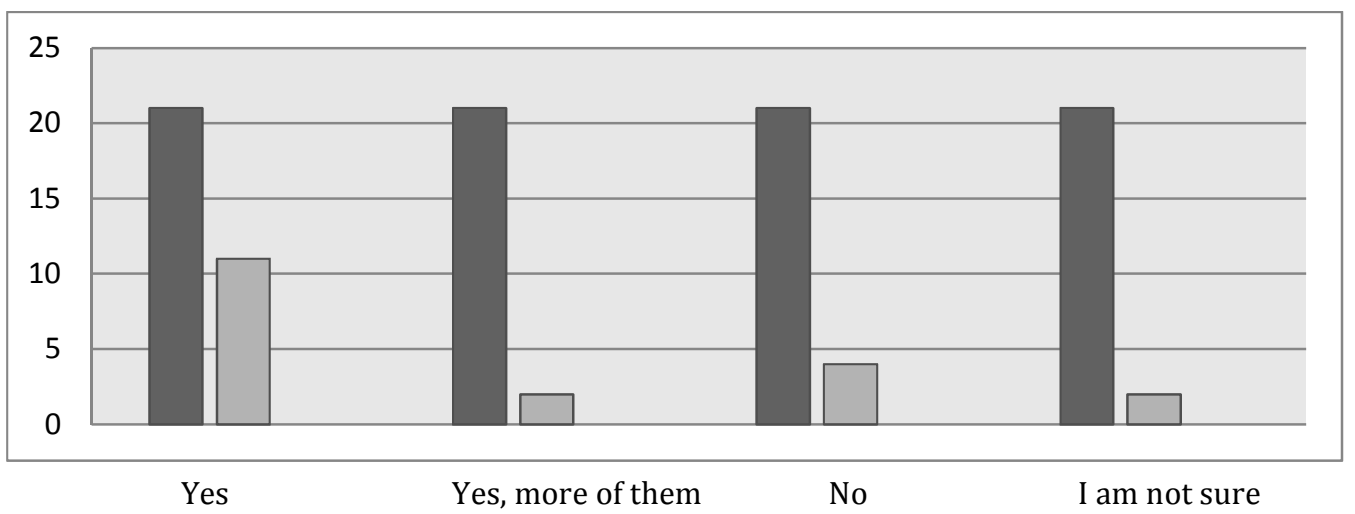

Chart 4: Has your municipality adopted the Local Environmental Action Plan (LEAP), the Local Agenda 21.

The Local Sustainable Development Strategy or another local strategic framework that regulates the issue of sustainable development?

One of the segments we wanted to process through this survey is certainly spatial planning and the problems that municipalities encounter on their way to achieving sustainable development through space planning. As can be seen in Chart 5. The most frequent problems are: insufficient funds, incomprehension of the principles of sustainable development, lack of willingness to implement, as well as insufficient knowledge, capacities and mechanisms for their implementation. The above facts speak about the necessity of further improvement of the existing staff, monitoring of the realized activities and the need for providing additional financial resources.

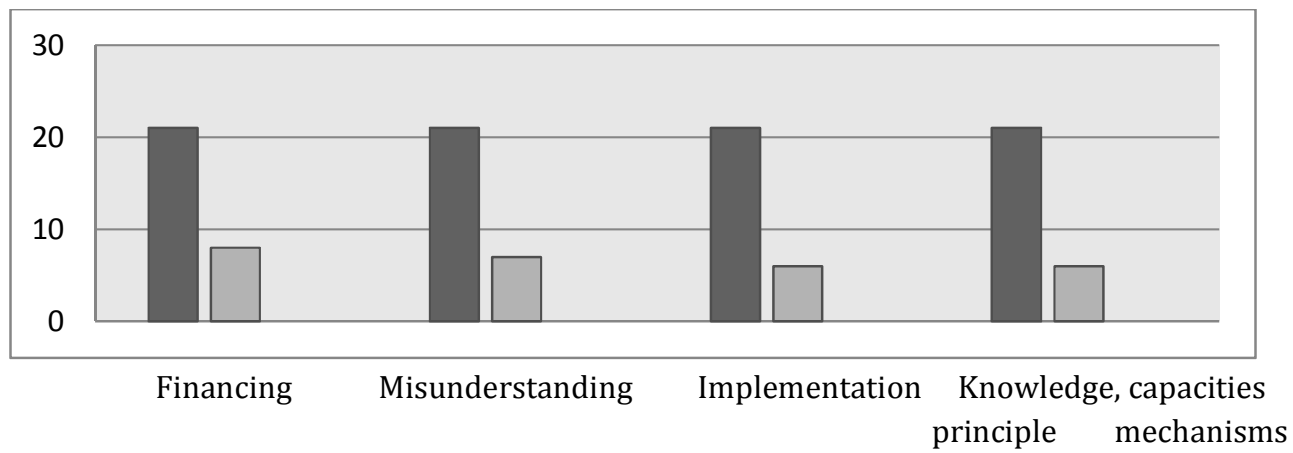

Chart 5: Problems faced by municipalities on the road towards achieving sustainable development?

5. In view of the growing problems in the field of environment, we wanted to find out which of the five environmental problems would be highlighted by the employees in the relevant municipal services as the most important ones in Montenegro. Almost all respondents pointed out the problem of waste disposal. An important place is the migration of people to cities, which creates additional pressure on the environment in certain areas. More pronounced problems are pollution of water and social and economic stratification of the population. The obtained results are presented in Chart 6.

6. The last set of questions concerned software tasks, i.e. Are municipalities managed by analyzes that bring about the real needs of the population and society as a whole and the use of space in the development of program tasks, and do they clearly define the valuable resources that will be preserved for future use? Needs and spatial capacity analyzes, as well as socio- 
economic analyzes are done in 10 municipalities, while demographic analyzes work in 7 out of 21 municipalities surveyed. None of the above analyzes is performed in the two municipalities.

Additional analysis was not mentioned in the responses, although there was a possibility for that.

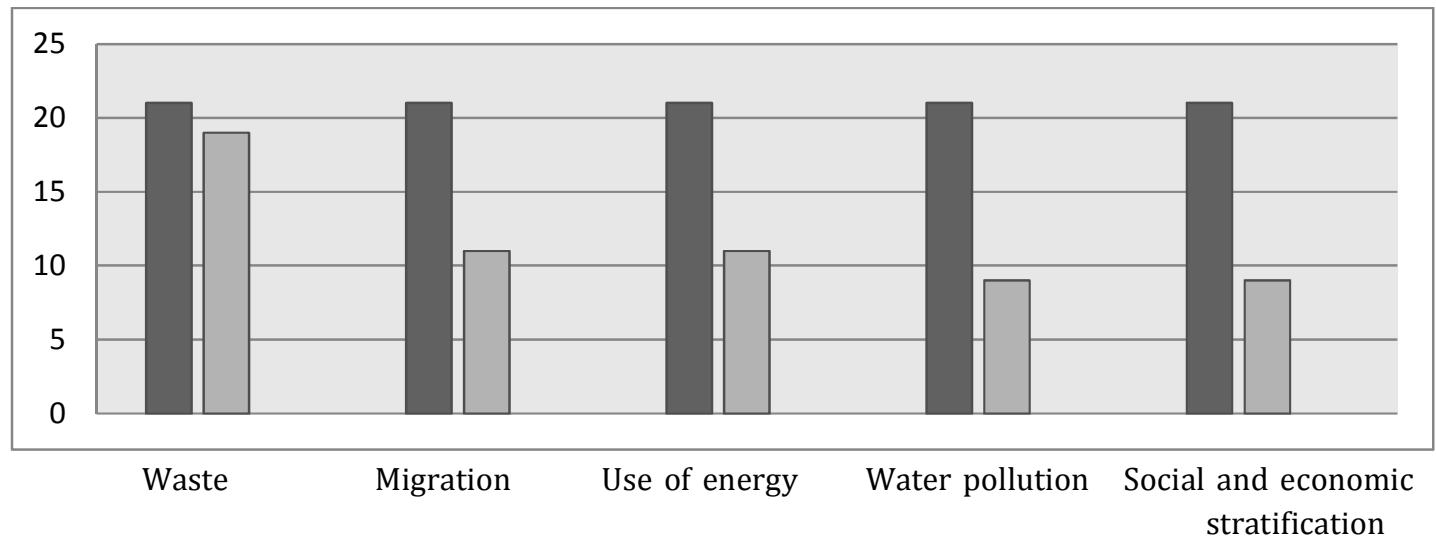

Chart 6: Five most common environmental problems in Montenegro

7. When it comes to defining value resources through probation tasks, the answers are unequal. Nine respondents point out that this issue is ignored in program tasks, while 6 consider this to be partial. The number of respondents who believe that this is not working or that they are not safe is the same ( 3 respondents). A graphic representation of the answer to this question is given in Chart 7.

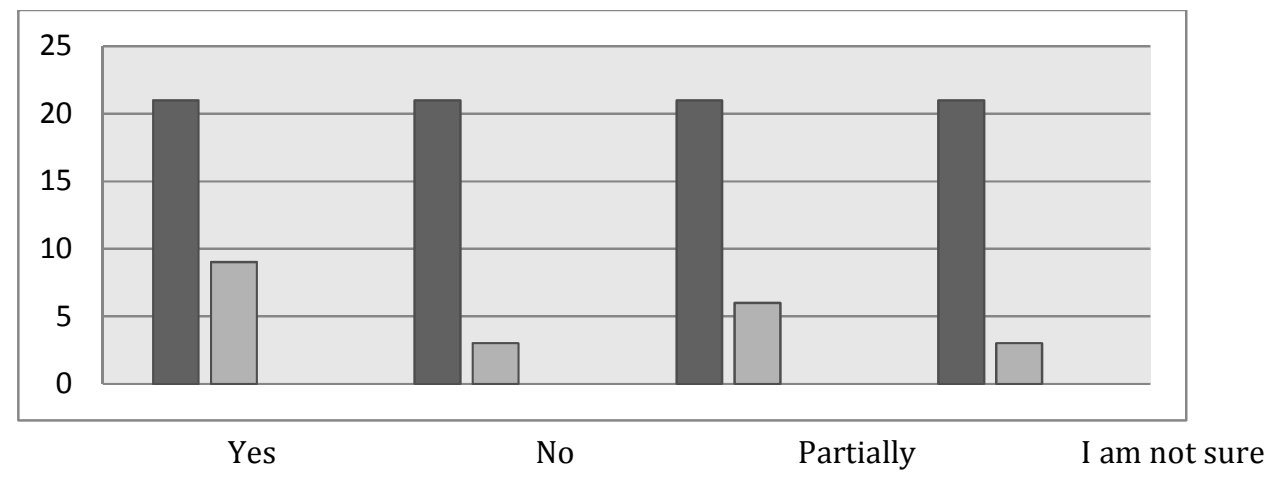

Chart 7: Does your municipality clearly define the valuable resources that will be saved for future use in the development of program tasks?

PART II Analysis of the survey intended for state authorities

1. Through the first set of questions, we wanted to determine how long the term of sustainable development is known to officials employed in state institutions, as well as a closer explanation of this term. Of the 14 respondents, all recognized the term sustainable development, as can be seen in Chart 1. 


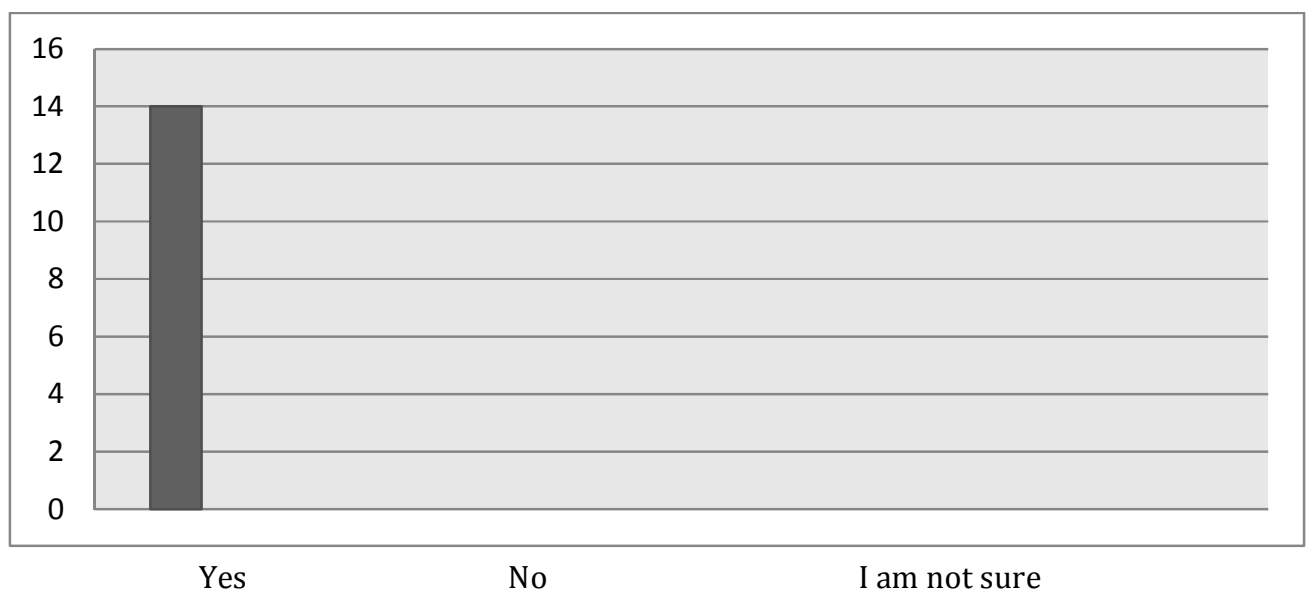

Chart 1: Do you know the term sustainable development?

Most respondents gave a full and identical definition of sustainable development: "Sustainable development is a concept that represents resource management in order to meet the needs of current generations in a way that does not endanger the ability of future generations to meet their needs."

In one case, we also had more definitions, the one most commonly used, in the report "Our Common Future" prepared by the World Commission on Environment and Development in 1987, to the most comprehensive: "Sustainable Development is an Integral Economic, Technological, social and cultural development, in line with the needs of protection and improvement of the environment, which enables present and future generations to satisfy their needs and improve the quality of life."

On the basis of the collected explanations, it can be claimed whether it is a real knowledge and understanding of terms, given the fact that most of the answers received are identical.

2. The principles of ecological, social, cultural and economic sustainability are the most important for most respondents, which can be seen in the graphic representation (Chart 2).

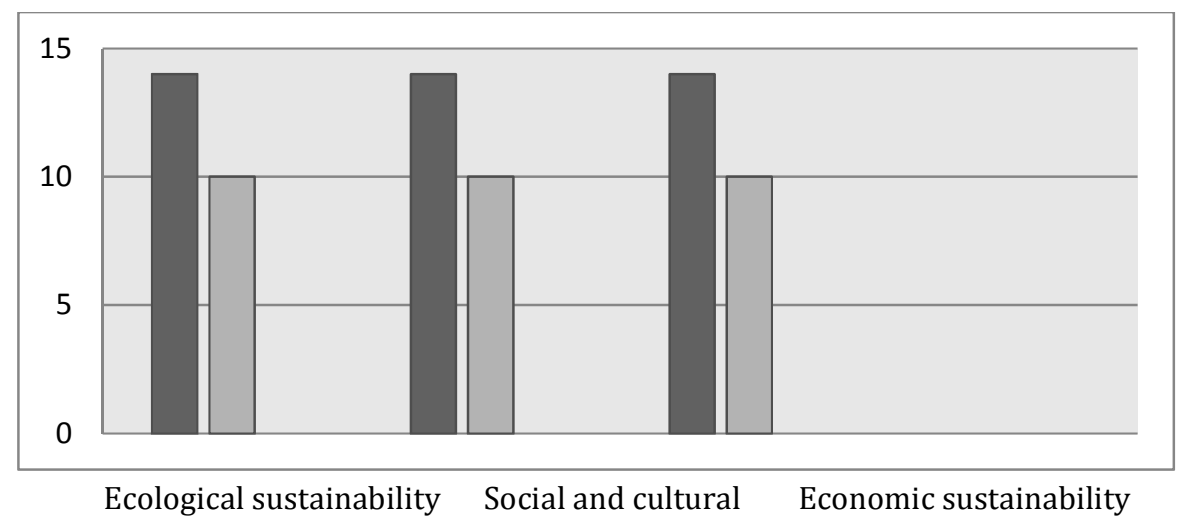

Chart 2: List the basic principles of sustainable development

3. A small number of respondents believe that an important role in sustainable development has: integrating environmental issues into development policies (3), the participation of all stakeholders in decision-making (3), and equality among generations and equality within the same generation and gender equality ( 3 ); 
The collected data indicate that the employees / do not know which are the most important principles of sustainable development.

3. A special part of the survey includes training related issues / training / seminars / conferences in the field of sustainable development. Of the 14 respondents employed in state institutions, 9 attended trainings / seminars / conferences in the field of sustainable development, which indicates that a significant number of employees have undergone some training, which can be seen in Chart 3.

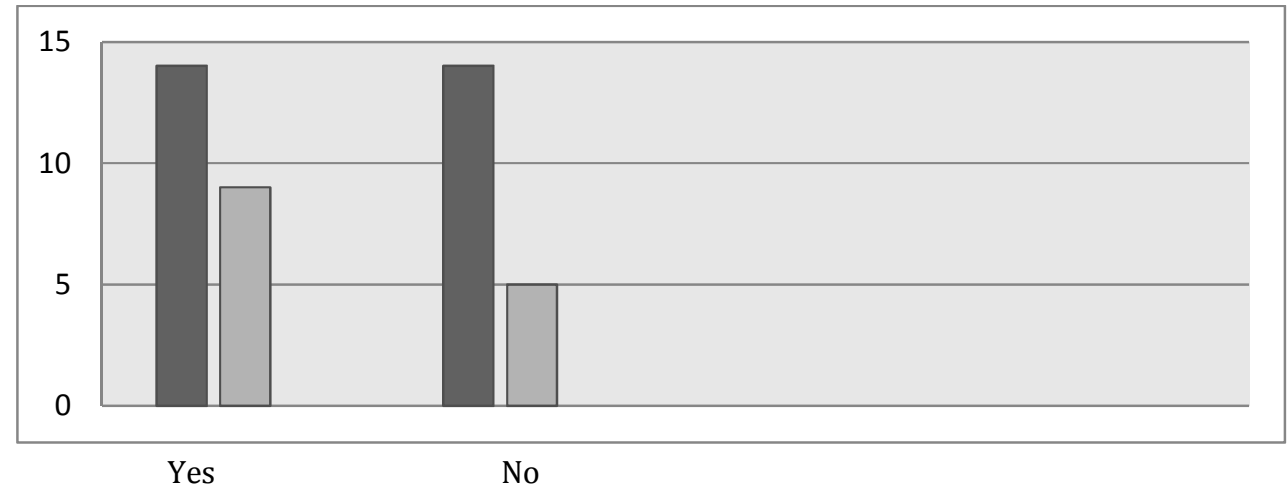

Chart 3: Have you been a participant in some trainings / seminars / conferences in the field of sustainable development?

Of respondents who attended trainings / seminars / conferences in the field of sustainable development, they were asked to specify what training was: From 9, one person did not indicate which training / seminars / conferences it was.

Most of the employees attended round tables on the topic of architecture and sustainable building, then spatial planning, the environment and the green economy. The data collected show that training should be focused on other activities in the field of sustainable development and organized in the form of high-level workshops with clear instructions for employees in state institutions.

5. Through the fourth issue, we wanted to find out what are the fundamental problems that Montenegro faces in pursuing the principle of sustainable development. According to the opinion of the civil servants interviewed, these are:

- Harmonization of plans and programs in the field of environment, energy, transport and tourism with the principles of sustainable development, as well as their implementation;

- Social inequality, insufficient development of system institutions, poor implementation and monitored legislation and difficult access to financial resources;

- Ignorance and misunderstanding of sustainable development, lack of adequate staff;

- Improving the environmental performance of products and increasing demand for sustainable products and manufacturing technologies;

- Improve cooperation, coordination and consultation between the various sectors within the Government, as well as between the Government and the private sector, as well as the need to improve regional cooperation so as to contribute to the achievement of a sustainable development pipeline;

- Making decisions on the environmental impact of social peace and economic development; 
- Low level of environmental awareness of citizens of Montenegro and insufficient commitment of the education system to environmental issues and the importance of sustainable development;

- The presence of private interest over the general, which leads to the short-term profit of an individual;

- Lack of systematic approach to planning and use of space;

- The unsolved problem of corruption.

The data collected indicate that government officials are aware of existing problems in order to achieve the principles of sustainable development, but also barriers to overcome in order to achieve the goals.

Graph 4 shows that the respondents consider that the disposal of waste and irrational use are the most frequent problems. Also, significant migration of population to cities, as well as pollution of industrial gases and contaminated water were also highlighted as a major problem.

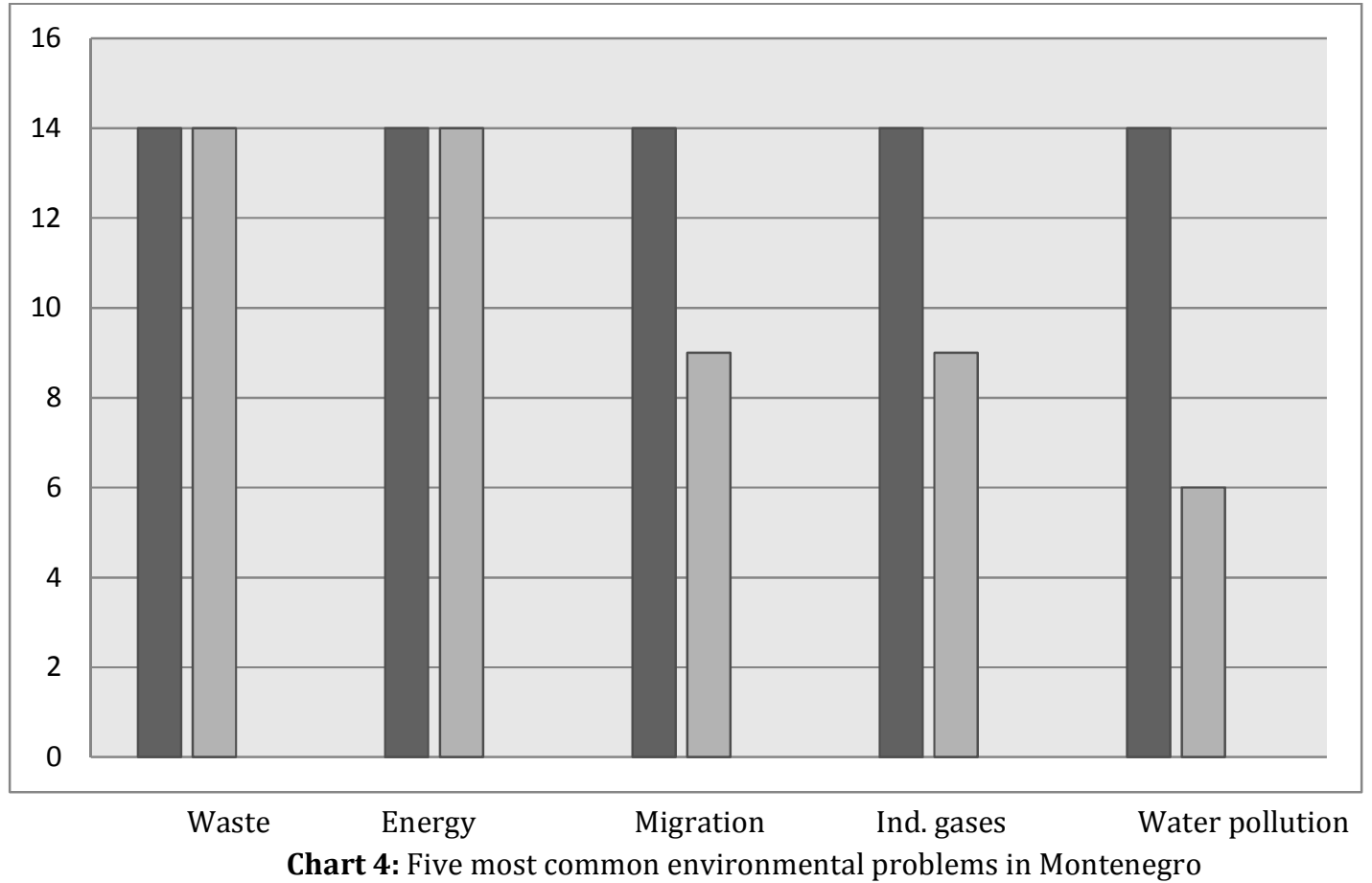

1. When it comes to the need to adopt additional regulations in the field of environmental protection and sustainable development, half of the respondents are not sure whether the adoption of additional regulations is necessary, which indicates that the employees are not familiar enough with the existing regulations in Montenegro and the degree their applications or do not want to answer this question. On the other hand, out of 14 respondents, 6 stated that changes to existing regulations were necessary, while one respondent considered it unnecessary. The graphic representation is given in Chart 5 . 


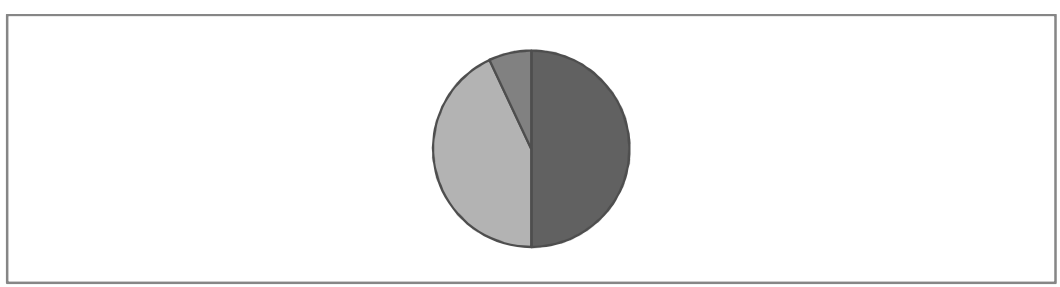

$50 \%$ Yes $43 \%$ No $7 \%$ I am not sure

Graph 5: Do you consider it necessary to adopt additional regulations in the field of environmental protection and sustainable development?

As part of this question, we interrelated in which areas changes of regulations are necessary. The answers are different and range from new laws on chemicals, noise and ionizing radiation, water management, waste management, eco-fund law, spatial planning, changes to all laws related to the environment, and the adoption of acts that would serve for checking the sustainability of policies, laws and strategies.

1. We were interested in the issue related to the environmental penal policy, whether it was appropriate. In the graph no. 6 it can be seen that most respondents consider that there is no proper environmental policy. On the other hand, since it is about employees in state institutions, it is worrying that a large number of those who are not safe.

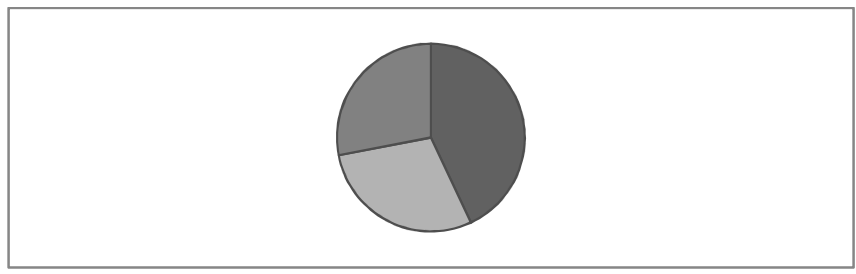

$43 \%$ Yes, $29 \%$ No, 28\% Not sure

Chart 6: Is there a proper environmental policy in the field?

In the explanations of the answer we reached the rating:

- That there is an adequate criminal policy, but that the implementation of the law and implementation of the penal policy is lacking;

- The necessity of educating citizens about the importance of preserving the living environment, as well as those employed in the competent state institutions and the judiciary, is emphasized;

- One of the problems is highlighting the decentralization of the system, since the units of local self-government still lack sufficient capacity to implement regulations such as waste management, noise, environmental impact assessment;

- Poorly positioned responsibility of the institutions responsible for environmental issues and inadequate mechanisms for their resolution;

- Lack of environmental law practice. There is no locus stand (the right to initiate an action in a court hearing or address to a court) for interested individuals, organizations and the public in general with regard to the environment.

8. When asked whether they are satisfied with the current situation in the field of environmental protection and improvement of the environment, half of the total number of respondents answered that it is partially satisfied, 4 of 14 people are not satisfied with the smallest number of those who are satisfied with the current situation. 
9. In addition, we were interested in priority fields of action in which post-environmental progress is necessary. Participants of the survey had the opportunity to give seven responses. The most common answers were: waste disposal and waste and waste water management, water protection, biodiversity protection and climate change (Chart 7).

Some of the respondents also stressed the importance of adopting appropriate legislation, its alignment with EU regulations, implementation, as well as strengthening institutional capacities and establishing an appropriate information system.

We also had recommendations on the importance of socially responsible business and the development of the green economy and the prevention of migration to cities.

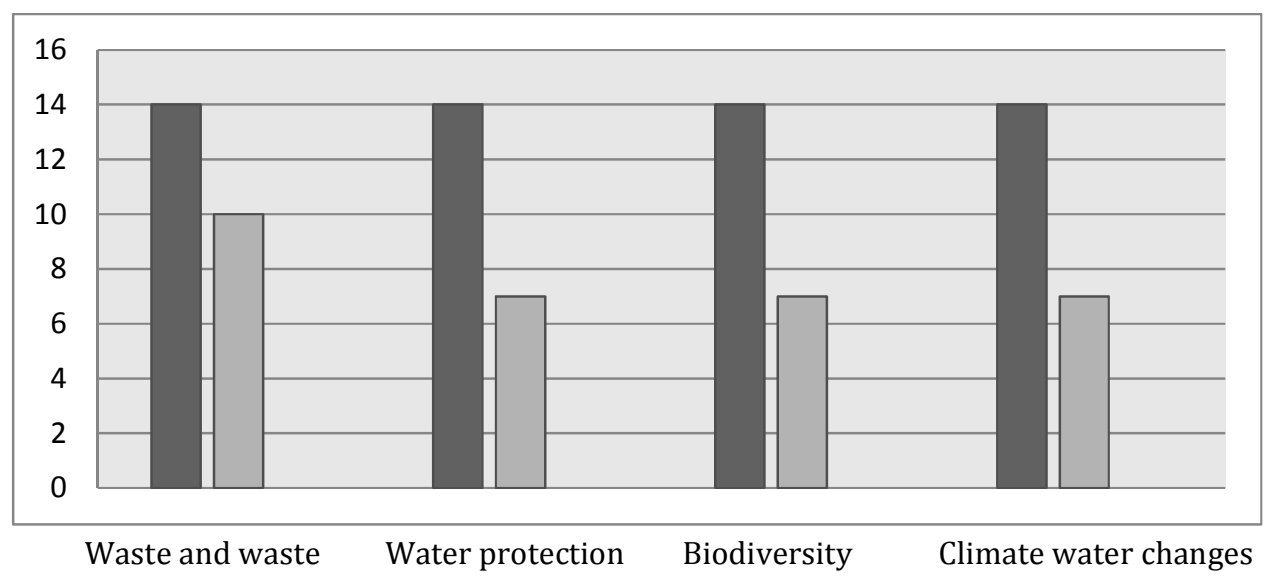

Chart 7. Priority fields of action in which progress in the field of environment is necessary

Some respondents emphasized the need for action in the fields of transport, tourism, regional development and employment, energy, agriculture, rural development and industry (3 respondents).

10. When asked about the harmonization of domestic legislation in the field of environment in Montenegro with the recommendations of the European Union, two out of the total number of respondents consider that environmental laws are largely in line with the EU recommendations, while three believe that the laws are harmonized, but it is necessary to work on the implementation of adopted regulations. Also, three respondents consider that the laws are sufficiently harmonized, but minor changes are minor. In addition, two respondents believe that the degree of harmonization depends on the area. Three respondents consider that they are not completely harmonized. One respondent believes that it is working on full harmonization.

\section{CONCLUSIONS}

The green economy has been promoted in recent decades as a very important change in thinking.

From the United Nations Conference on Environment and Development in 1992, sustainability is becoming a widely accepted goal. Although information can provide a better basis for decision making and measuring progress, accountability can only be achieved if goals and measures of progress are explicitly stated. Properly formulated indicators can provide such measures, improving the diagnosis of the situation, both progress and regression.

In both surveys, whether intended for municipalities or civil services, several areas are distinguished:

- Knowledge of the term sustainable development and its principles;

- Part that relates to capacity building of employees; 
- Key problems in the field of environment in Montenegro and priority fields of action;

- Legislation, both at national and local level;

- The situation in the field of criminal policy.

The vast majority of surveyed state and municipal officials recognize the term sustainable development and the basic principles of sustainable development. When it comes to the closer explanation of this term, we can not claim to fully understand its meaning, given the fact that we have received a large number of identical explanations.

We found that employees attended trainings / seminars / conferences whose topic was only one of the segments of sustainable development, which indicates the need to further improve and strengthen the capacities of competent state and municipal services.

Through these tests, we obtained a confirmation that employees in state bodies and municipalities also share opinions with citizens that in Montenegro the problem of waste disposal is currently the most serious and that it requires fast and efficient resolution. Rational use of energy, expressed migration of population, problems of pollution of water and air are emphasized as priority problems.

According to the answers received, the opinions of civil servants are divided when it comes to the changes in existing regulations in the field of environment in Crna Gora and range from those who are not sure that the changes are needed to those who deem it necessary. The minimum number of respondents considers that changes should not be made. Opinions on compliance with EU regulations are divided. Very few believe that domestic laws are not in line with the relevant obstacles of the EU. The majority of respondents think that the laws are harmonized or that minor changes are needed. The issue of implementation of existing laws was emphasized.

It is also pointed out that there is no appropriate environmental penal policy. On the other hand, since it is about employees in state institutions, it is worrying that a large number of those who are not sure whether the existing criminal policy is appropriate.

Different types of analysis are carried out in the preparation of program tasks, with a very small number of municipalities doing all the above analyzes. Integrating issues of valuable resources through program tasks is also done in a small number of municipalities, and often only partially done.

Environmental awareness, expressed the interest to rationalize the exploitation of natural resources, especially non-renewable, in caring for the conservation of wildlife diversity (biodiversity) on Earth, in caring for the protection of the quality of the human environment including the socio-political and economic developments, not as decorative philosophical declaration, but as a permanent element in the practical design and implementation of business and other ventures. For the purpose of effective implementation of objective knowledge and theoretical concepts of modern science of nature, find the exact new measures and indicators. Really, not a formal environmental assessment of development programs becomes a mandatory component of the economic planning. Modern macroeconomics is faced with the task of promptly assimilated by ecological insights and predictions, both local and global, and to anticipate and provide their implications.

\section{REFERENCES}

Georgescu-Roegen, N.R. 1971. The Law of Entropy and the Economic Process.

M. and associates 1972. The limits to growth. New York: Universe books.

Beard, R., \& Lozada, G. 2003. Economics, Entropy and the Environment. Journal of Bioeconomics 5.

Bell, S., \& Morse, S. 1999. Sustainability Indicators: Measuring the Immeasurable? Erthscan Publications Limited. 
Bossel, H. 2001. Assesing Viability and Sustainability: A Systems-Based Approach for Deriving Comprehensive Indicator Sets.

European commision. 1999. European Spatial Development Perspective, Towards Balanced and Sustainable Development of the Territory.

European commision (211). The European Eco-Management and Audit Scheme.

International Network for Environmental Compliance and Enforcement . (2012).

IUCN - International Union for Conservation of Nature. 1991. Caring for the Earth, A Strategy for Sustainable Living. Gland, Switzerland.

Mirowski, P. 1989. More Heat than Light: Economics as Social Physics, Physics as Nature's Economics (Historical Perspectives on Modern Economics). Cambridge university press.

Natasa, P., Slovic, D., \& Cirovic, D. (n.d.). Indikatori ekoloških performansi kao smjernice ka održivosti. Fakultet organizacionih nauka.

Neimanis, V. a. 1996. Developing national environmental indicators. . Rotterdam: A.A. Balkema.

Tickell, C. 1997. The human species: A suicidal success' in Goudie. A. (ed.). The Human Impact Reader: Readings and Case Studies, pp. 450-460.

UNCED. (n.d.). Agenda 21: Programme of Action for Sustainable Development. Rio Declaration on Environment and Development. New York: United Nations.

Unija poslodavaca Crne Gore. 2017. Istraživanje o zelenoj ekonomiji i zelenim poslovima.

World Bank. 2003. Sustainable development in a dynamic world: Transforming institutions, growth, and quality of life. Oxford University Press.

World commission on Environment and Development. 1987. Our Common Future - The Bruntdland Report.

\begin{tabular}{l|l} 
Article history: & Received: February 26, 2018
\end{tabular}

Accepted: May 4, 2018 